\title{
Soil-Root System Withholding Strength for River Bank Stability
}

\author{
(Date received: 14.06.16/Date accepted: 08.08.16)
}

\author{
${ }^{1}$ Ding Ibau, B.Eng (Hons). and ${ }^{2}$ Ir. Prof. Dr Ruslan Hassan, Ph.D., P.E. FASc. \\ Malaysia Institute of Transport (Mitrans) \\ UiTM, 40450 Shah Alam, Selangor
}

\begin{abstract}
The ability of vegetation to stabilise soils is frequently employed in slope stabilisation projects including riverbank restoration activity. Soil block samples permeated with roots of Bermuda Grass commonly used for remediation and riverbank restoration were tested in a direct shear apparatus. Shear stress results of rooted soils were compared with results of un-vegetated soil blocks with similar soil types. The increase of shear strength was determined by comparing shear stresses at specific horizontal displacements. The relative strength increase at the same displacement was $27.3 \mathrm{kPa}$ compared to $19.1 \mathrm{kPa}$ for un-vegetated soil at a displacement of $13.3 \mathrm{~cm}$ (Location 3). The relative strength increase at the same displacement of $13.3 \mathrm{~cm}$ was $43.5 \%$ for Location 1 and 42.4\% for Location 2. The shear stresses in most of the blocks with roots were still increasing at the end of the test (maximum displacement of about $15 \mathrm{~cm}$ ). These conservative root biomass values and the shearing resistance obtained can be used in the assessment of the stability of the existing vegetated slopes and in the design of vegetated riverbanks.
\end{abstract}

\section{INTRODUCTION}

The physical vegetative coverage on stream-banks provides underground soil reinforcement and surface protection from scour. The level of vegetation for protecting soil depends on the combined effects of roots, stems and foliage. Root systems aid stream-bank stabilisation through soil-root interaction. The mechanics of root-reinforcements are similar to the basic mechanics of engineered reinforced-earth systems. Vegetation installed on slopes and stream-banks provides resistance to shallow mass movement by counterbalancing local instabilities.

\section{BACKGROUND: STABILISING MECHANISMS}

For stabilisation techniques that rely on vegetative materials, the stabilisation is vulnerable at the early stage but becomes stronger as the vegetation is established. The primary stabilising mechanisms include: (a) Reinforcing the soil with tensile fibres of the root mass, (b) Increasing shear strength by reducing pore-pressures through transpiration, (c) Anchoring the slope through deep root penetration into more stable strata, and (d) Decreasing the flow velocities and dissipating the flow energies by redistributing the flow pattern and direction by the foliage and stems of shrubs.

Perhaps the most complete overview of soil reinforcement by roots and artificial fibres is provided by Gray and Sotir [1] The basic process involves the transfer of shear stress within the soil to tensile resistance of the roots, which becomes a function of the interface friction along the root surface. The orientation of the fibre relative to the shear force, the skin friction of the root, the elongation behaviour of the root, the fraction of the soil cross section occupied by roots, and the tendency to break rather than pull out are all factors influencing the reinforcing effect. Over the last 60 years, data related to limits of vegetal reinforcement have been presented both in terms of shear stress (or tractive force) and flow velocities. Shear stress, in $\mathrm{N} / \mathrm{m}^{2}$, is a preferred measure because it considers several variables including depth, the wetted channel perimeter, and flow velocities. In addition, failure criteria for a particular lining is represented by a single shear stress value, applicable over a wide range of channel slopes and shapes. For these reasons, this paper will present vegetal resistance in terms of shear stress.

\section{THEORETICAL CONSIDERATION}

Soil is strong in compression but weak in tension and roots are weak in compression but strong in tension. Therefore when soil and roots are combined the resultant soil-root matrix produces a mass which is much stronger than either the soil or the roots on their own. The roots act by transferring the shear stresses developing in the soil to the tensile resistance in the roots, and also by distributing stresses through the soil, so avoiding local stress build-ups and progressive failures. These will be highly dependent on the contribution of root density.

The theory of reinforced earth was first developed by Vidal [2]. As a vertical principal stress is applied to an unconfined element of soil the element will strain laterally as it compresses axially (Figure 1). If reinforcement is added to the soil in the form of horizontal strips, the lateral movement induced in the soil generates a frictional force between the soil

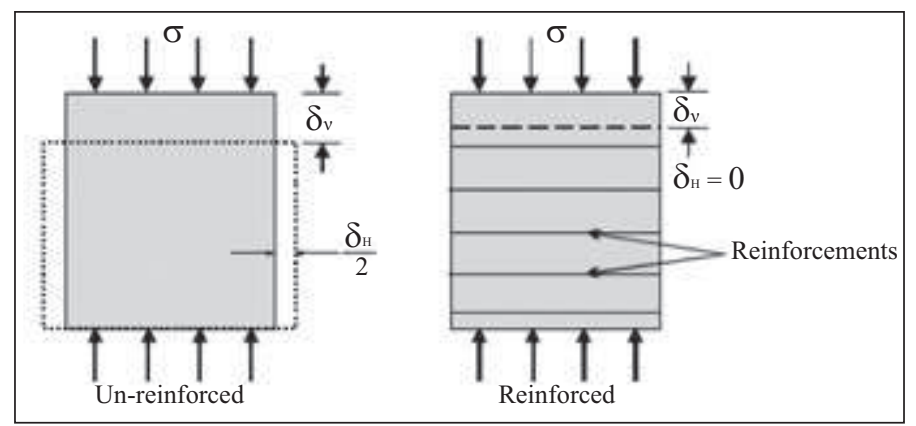

Figure 1: The Action of Reinforcements on A Cohesionless Soil Element

Note: The Reinforced Element Resists Lateral Expansion Through The Mobilisation of A Frictional Force Between the Soil and the Reinforcement [3] 
and the reinforcement. As a tensile force develops within the reinforcement a corresponding compressive lateral confining stress is generated within the soil. This lateral confining stress is analogous to an externally applied confining pressure and is proportional to the applied normal confining stress up to a limit defined as the 'critical confining stress'. The action of reinforcement in soil is therefore not one of carrying developed tensile stresses but of the anisotropic reduction or suppression of an applied normal strain rate. This suppressive mechanism leads to the concept of anisotropic cohesion.

Some studies indicate that the increase in apparent soil cohesion is limited to roots up to about $2 \mathrm{~cm}$ in diameter [4]. Beyond this size the reinforcing effect is thought to be largely due to a root's ability to anchor a relatively weak layer of soil across a discontinuity, the shear surface, to an underlying stronger soil or bedrock. The justification for this limit is not completely clear as field studies often cited as supporting it $[5,6]$, although demonstrating the importance of small roots to increased soil shear strength does not actually measure the effect of larger roots. Burroughs \& Thomas [5] measured roots up to $1 \mathrm{~cm}$ in diameter, and O'Loughlin \& Watson [6] up to $3 \mathrm{~cm}$. An extensive literature search was unable to locate any study that assessed the reinforcing actions of roots of different sizes. There are also many examples of small roots $(<2 \mathrm{~cm}$ diameter $)$ acting or suspected as acting like ground anchors by growing into discontinuities and fissures in the bedrock or more stable substrate $[7,8]$. It is generally agreed that apart from an increase in apparent soil cohesion roots may also increase the shear strength of a soil by an anchoring mechanism.

\section{A. Root system}

Investigations of root system architecture include those undertaken on vegetative crops for growth analysis [9, 10], mathematical models of root structure form and geometry [11, $12,13,14,15]$, and general rooting habits as they relate to site conditions and processes $[16,17.18]$. Evidently there is an extremely wide range in root geometry from species to species (Figure 2) and so it is difficult to transfer data directly from one site to another because of the influence of local site conditions on root growth [19]. Different rooting habit and site condition will influence the root biomass density. This theory also agreed by Todd, et al., [20]; for different species of vegetation will give different root geometry and this will give different values of density. The plant species, root density, and stem height were inconsistent because of variation on soil types.

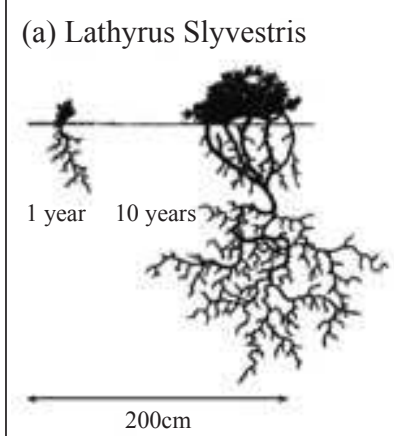

(b) Artemesia vulgaris

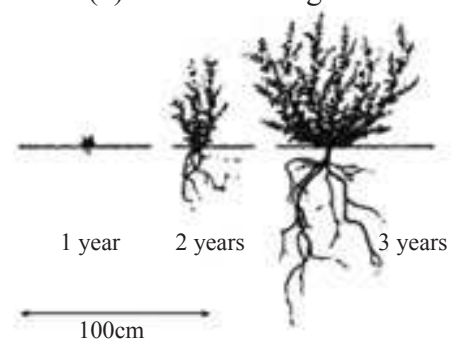

Figure 2: Some Examples of the Wide Variety In Root Geometry of Different Species. (a) Lathyrus Sylvestris and (b) Artemesia Vulgaris (After Schiechtl [21])

\section{B. Soil Mass Shear Strength}

The strength of soil is difficult to be measured directly. Evaluating the effect of roots on soil strength increases that difficulty. In 1968 a shear box was developed to measure the contribution of small alder (Alnus glutinosa) roots to the strength of relatively homogeneous nursery soil in Japan. The weight of roots attained $53 \%$ of the variation in measured soil strength. The shear box was later modified to study the contribution to soil strength by roots of a mixed old-growth forest of Douglasfir (Pseudotsu-gamenziesii), western redcedar (Thuja plicata), and western hemlock (Tsuga heterophylla) growing on glacial till sub-soils in British Columbia, Canada. The weight of roots in the soil sample was the most significant of seven variables tested, accounting for $56 \%$ of the variation in measured soil strength. Shear box was used in the testing of relatively simple soil-root system of a mature shore pine (Pinus contorta) forest growing on coastal sands in northern California. The dry weight of the live roots less than $17 \mathrm{~mm}$ in diameter was the significant variable contributing to soil shear strength among the soil and vegetative variables tested. The shear box tests resulted in Eq. (1), in which soil strength is in kilopascals and root biomass is in kilograms per cubic meter.

Soil strength $=3.13+3.31$ root biomass

The equation attains $79 \%$ of the variation in measured soil strength. The mean biomass of the less than $17-\mathrm{mm}$-diameter live roots was $1.77 \mathrm{~kg} / \mathrm{m}^{3}$, which represented $64 \%$ of the total root biomass. To evaluate the contribution of root in the strength of soil-plant mass, dry density biomass of vegetative is a dominant component in relation to the soil strength.

\section{Significant Roles of Roots System and Configuration}

Roots system plays significant role in plant-soil mass in order to improve slope and prevent soil erosion. There has been a long held belief that erosion control performance by vegetation relates to the additional strength provided by vegetation roots to the soil as well as the ability of the above-ground parts to intercept and transpire water. The role played by vegetation in improving slope stability and preventing soil erosion is well recognized [22, 23, 24].

In order to evaluate the contribution of vegetation roots to soil shear strength (i.e. to determine $S_{r}$ ) a simple model was developed independently by Waldron (25) and Wu et al., [26]. The model was designed to simulate the idealised situation of

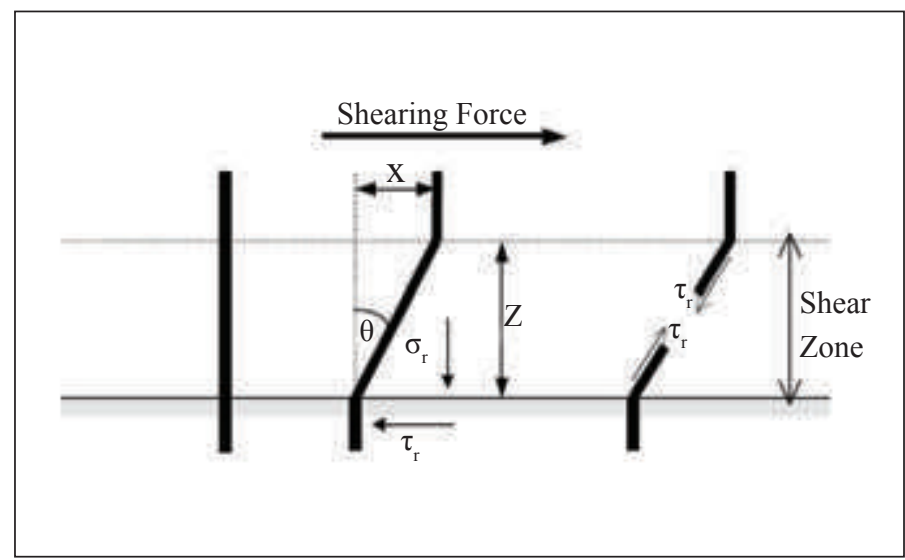

Figure 3: Model of A flexible, Elastic Root Extending Vertically Across A Horizontal Shear Zone 
vegetation's vertical roots extending across a potential sliding surface in a slope. It consists of a flexible, elastic root extending vertically across a horizontal shear zone of thickness $\mathrm{z}$ (Figure $3)$.

$\tau_{\mathrm{x}}=\tau_{\mathrm{s}} \sin \theta$ and $\sigma_{\mathrm{x}}=\tau_{\mathrm{s}} \cos \theta$

As the soil is sheared a tensile force $T_{r}$ develops in the roots. As shown in Figure 3 this force is resolved into a tangential component $\left(\mathrm{T}_{\mathrm{r}}\right)$ which resists shear and a normal component $\left(\tau_{\mathrm{r}}\right)$ which increases the confining stress on the shear plane

where $\left(\tau_{r}\right)$ and $\left(\sigma_{r}\right)$ are the tangential and normal stresses applied to the soil by $\mathrm{T}_{\mathrm{r}} ;\left(\tau_{\mathrm{s}}\right)$ is the average tensile strength of roots per unit area of soil; and $\theta$ is the angle of shear distortion of the root.

$\mathrm{S}_{\mathrm{r}}=\sigma_{\mathrm{x}} \tan \phi+\tau_{\mathrm{x}}=\tau_{\mathrm{S}}(\cos \theta \tan \phi+\sin )$

The contribution of the root to shear strength is then given by:

where $\phi=$ angle of internal friction.

The average tensile strength of the roots per unit area of soil

$$
\tau_{\mathrm{s}}=\mathrm{T}_{\mathrm{s}}\left(\mathrm{A}_{\mathrm{s}} / \mathrm{A}\right)
$$

$\left(\tau_{\mathrm{s}}\right)$ is determined by multiplying the average tensile strength of the roots by the fraction of the shear surface cross section occupied by roots:

\section{METHODOLOGY}

The study involved both field and laboratory studies. Soil blocks were obtained from a site at Jenderam Hulu River in Sepang. The samples were taken from 4 locations at the site and all the testing and analysis were carried out in the Water Laboratory and Advanced Soil Laboratory. The soil blocks from the riverbank were considered very suitable for this study because the plants (Bermuda grass (cynodon dactylon) were all growing in close proximity and access was possible. The location for each of the samples is shown Figure 4.

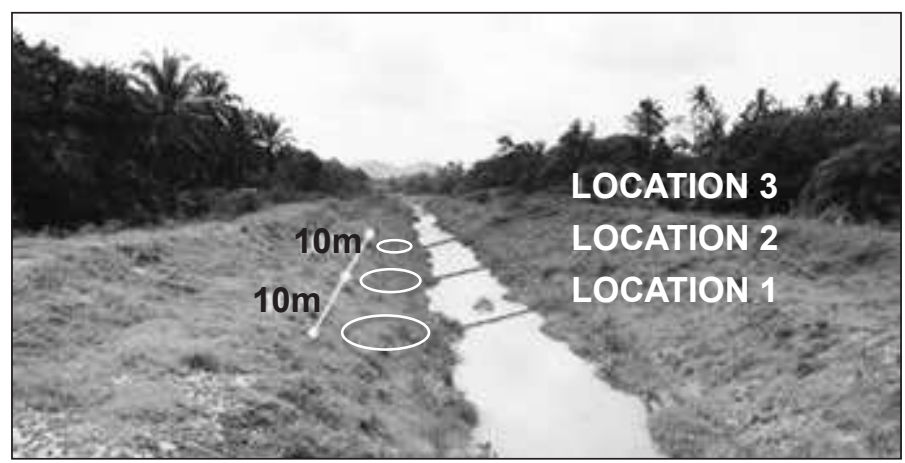

Figure 4: Sampling Locations

\section{A. Materials and Methods}

Four sample blocks of soil (each location) were removed from a riparian environment with caution to minimize disturbance of soil structure. All samples were carefully carved to dimensions of $100 \mathrm{~mm}$ by $100 \mathrm{~mm}$ by $30 \mathrm{~mm}$ depth. Samples from the bare location contained no vegetation, but serve as a typical soil. Samples from location 1, 2 and 3 (Figure 4) contained the single specimen of vegetative, estimated at 2.5 years in age, with roots radiating throughout the soil block.

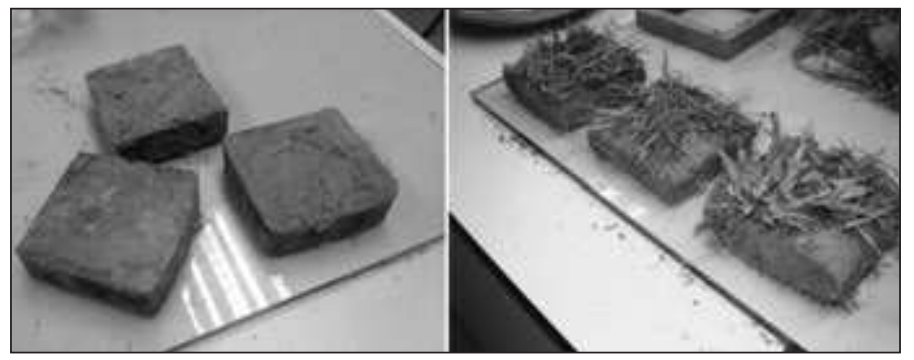

Figure 5: Samples of Vegetated Location (w/out vegetation), 1,2 and 3)

When samples were collected and tested, the soil moisture levels were at the field capacity. The shear box machine (ELE International) was used in this study. The block samples were taken using a sharp edged metal plate box with dimensions of $100 \times 100 \times 30 \mathrm{~mm}$. All samples had been carefully carved and removed with caution to minimize disturbance. Three block samples were obtained for the 4 locations making a total of 12 block samples. The distances between samples were kept to a $1 \mathrm{~m}$ radius and $10 \mathrm{~m}$ for each location containing vegetation to obtain blocks with similar soil types. Efforts were made to select uniform soil conditions, although the plants tended to be distributed according to variations in soil and hydrology (moisture content).

\section{B. Shear Test Description}

A direct shear apparatus shown in Figure 6 was modified to perform shear tests on the soil blocks. The dimensions of the shear box were selected to accommodate the soil blocks. Soil specimens were placed in the shear box machine. Where applicable, excess top growth was trimmed to facilitate handling and small gaps at the edges of the sample filled with identical soil using as low compaction effort. Load (stress) and displacement (strain) were plotted throughout the duration of the test procedure. A nominal normal load was applied in the form of a $2 \mathrm{~kg}$ metal plate to aid in the containment of the specimens during the test procedure; however, no other significant normal load was maintained in order to simulate natural surface soil conditions. The testing methodology followed ELE International procedure. All samples were tested with the matrix potential brought as close as possible to zero at the shear plane. A load cell was installed to measure the shear forces and an electronic device measured the horizontal displacements. Information from these two measuring devices was sent to the data logger (digital shear machine), which in turn fed the data into a computer. After the completion of the test, photographs of the sheared surface were

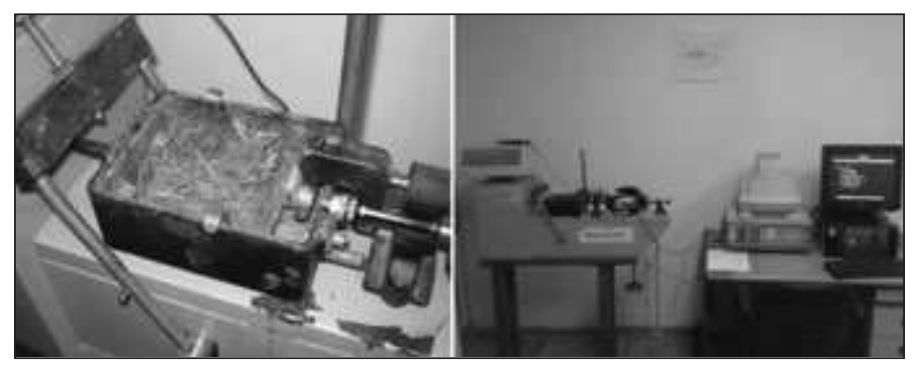

Figure 6: Soil Block Placed in the Shear Box

taken, and the roots and top growth were removed to measure the dry biomass. The soil from each block (location of typical soil) was mixed and a sample taken for conducting a grain-size distribution analysis. 


\section{Dry Biomass Test}

Dry root biomass density is the dry weight of roots divided by the volume of the block sample used in the shear test. After the soil blocks were sieved, all roots were extracted, washed, and separated into live and dead fractions, dried at $700^{\circ} \mathrm{C}$ and weighed. From each test location, data were collected for soil and root variables. The results of the average root biomass density were then plotted.

\section{RESULTS}

Shearing tests were performed on soil blocks that contained roots to study the contribution of roots to the shear strength in a case where the shear deformation is constrained to a thin zone. The shearing resistances of the soil-root system and the biomass of selected roots were measured. Additionally particle size and the moisture content plus the soil block were measured to determine the type and characteristics of soils. The roots were exposed after the test and their orientations and variation within the soil blocks were observed and used to explain the shear strength value. The root biomass and the shearing resistance of the soil-root system were estimated with known solutions and compared with all the theoretical data. None of the roots that passed through the shear zone failed in tension at the maximum displacement. As a consequence, the root resistance is much less than that found in a case where the failure surface is restricted to the boundary between a weak soil and a firm base and where roots are anchored in the firm base and fail in tension.

\section{A. Soil-Plant Shear Strength}

Shear stress vs. horizontal displacement curves are shown in Figures 7 to 10 for representative tests of each location and for the un-vegetated soil. The shear stresses in different root permeated soil samples changed in different ways as the soil block was displaced because of their different root orientations. Additionally, there were no major drop in shear stress of most of the samples suggests that the roots had not failed in tension yet. The shear stresses in most block samples, were still increasing at the end of the tests. As a result, peak stresses and residual stresses were not clearly identified from these plots. The method adopted to assess the shear strength increase was to compare them at a specific horizontal displacement.

The maximum shear stress achieved in the un-vegetated soil was about $19.1 \mathrm{kPa}, 18.1 \mathrm{kPa}$ for sample 3 and both sample 1 $\& 2$, respectively. A shear force versus horizontal displacement plot (Figure 7) for the un-vegetated soil blocks was used to determine the displacement at which the maximum shear

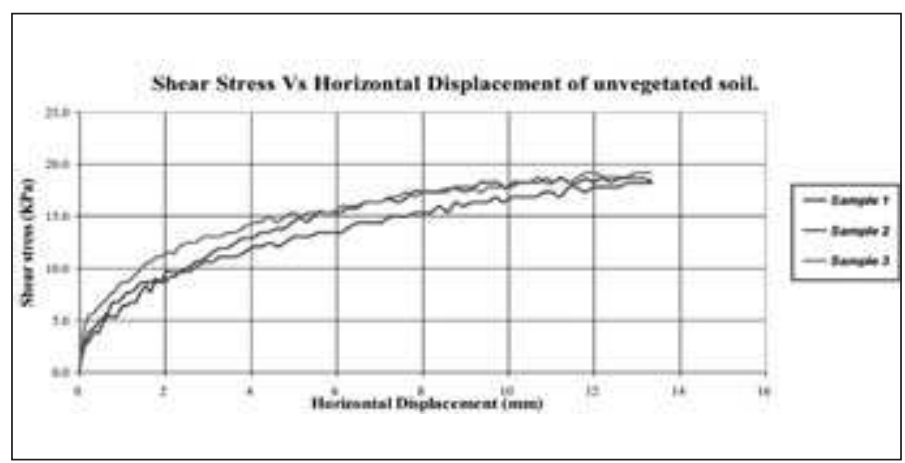

Figure 7: Shear Stress VS, Horizontal Displacement for Represntative Samples of Unvegetated Soils

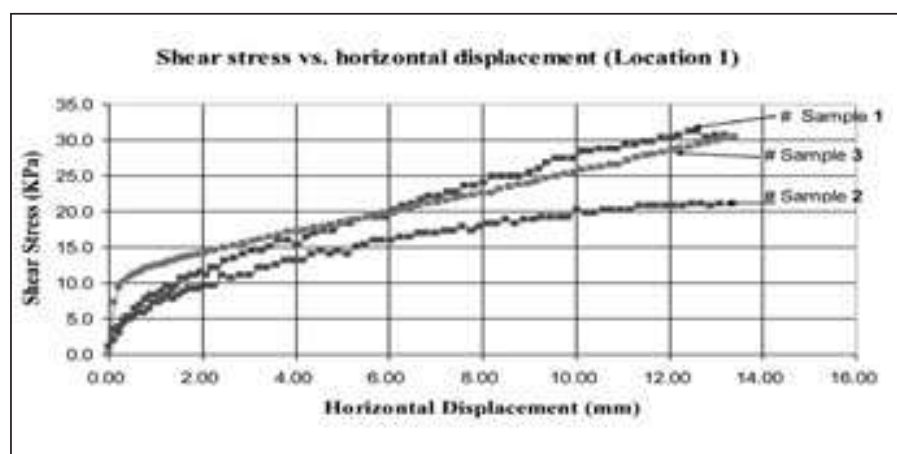

Figure 8: Shear Stress VS. Horizontal Displacement for Representative Samples

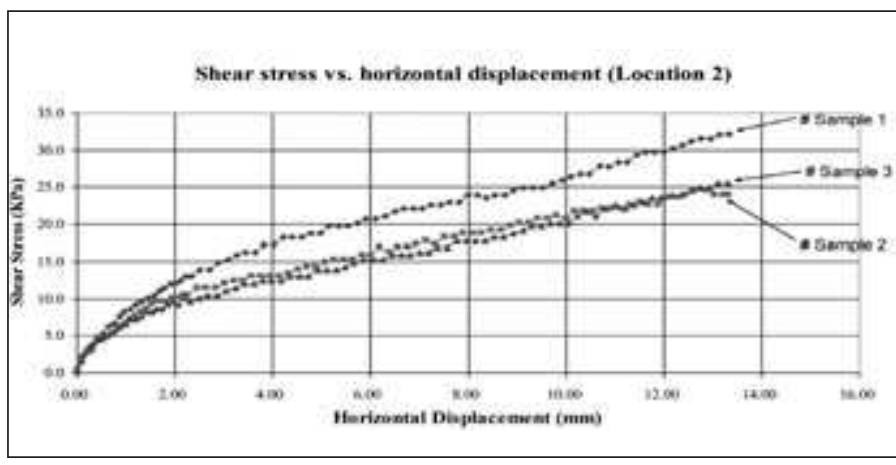

Figure 9: Shear Stress VS. Horizontal Displacement for Representative Samples

force occurred. 1. On average, the maximum force occurred at displacement $11.8 \mathrm{~cm}, 12.8 \mathrm{~cm}$ and $13.3 \mathrm{~cm}$. Therefore, stresses at these displacements were used to characterize the soil shearing resistance. In addition, stresses at $4 \mathrm{~cm}, 6 \mathrm{~cm} 8 \mathrm{~cm}$ and $10.8 \mathrm{~cm}$ were also included for comparison. A graph of the average shear stresses at these three different displacements is presented in Figure 11. An analysis of data using statistic was conducted using the data of shear stress occurring at a displacement of $4 \mathrm{~cm}$, $6 \mathrm{~cm}, 8 \mathrm{~cm}, 10.8 \mathrm{~cm}, 11.8 \mathrm{~cm}, 12.8 \mathrm{~cm}$ and $13.3 \mathrm{~cm}$.

Sample one, un-vegetated soil, showed an ultimate shear stress of $19.1 \mathrm{KPa}$ and a residual shear stress of $18.8 \mathrm{KPa}$. These values are typical of soils of similar particle size distribution at field capacity moisture levels. Visual inspection of the sample indicated that shear failure had occurred along a well-developed plane dissecting the entire soil block.

Three samples, rooted with Bermuda grass at location 1, was tested until the full displacement capacity of the shear box machine had been utilized. The applied shear stress continued to climb steadily until a final reading of $30.6 \mathrm{KPa}, 21.1 \mathrm{KPa}$ and $30.6 \mathrm{KPa}$ for samples 1,2 and 3 respectively (Figure 8) was taken before the test was terminated. Visual inspection of the sample indicated that shear deformation was distributed across a shear plan of soil reinforced by fibrous roots. This mode of shear deformation has been described by other investigator [26] as typical for soils with fibre inclusions. The magnitude of the shear resistance without discrete failure of soil structure was significantly higher than for un-vegetated soils, although the deformation mechanisms were the same. Reinforcement of soil by a substantially high density of fibrous roots, in this case, appeared to increase the strength of soils while also altering the failure mechanism. Interestingly, the plant and all its roots remained intact throughout the test procedure. 


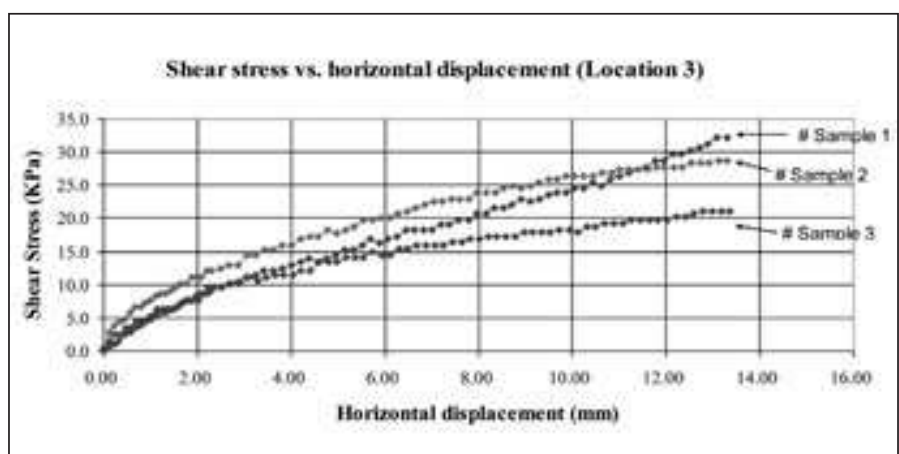

Figure 10: Shear Stress VS. Horizontal Displacement for Representative Samples

Another 3 samples, rooted with the same grass at location 2, showed an ultimate shear stress of $32.2 \mathrm{KPa}$ and a residual shear stress also $32.2 \mathrm{kPa}$ (Figure 9 - sample 1). The observed failure mechanism was essentially identical to the un-vegetated soil, and noticeably slightly different from the samples at location 1, apparently due to the relatively low density (root biomass density) of fine fibrous roots as compared with the location 1 and 3. Both ultimate and residual shear stress values are higher than for un-vegetated soil, indicating the reinforcing value of the roots. Effects on the orientation, variation and morphology of the vegetation seem to give different value of shear resistance.

The last three samples from location 3 also rooted with the same types of grass showed value of maximum shear stress of $32.2 \mathrm{kPa}, 28.7 \mathrm{kPa}$ and $21.1 \mathrm{kPa}$ for sample 1,2 and 3 respectively (see Figure 10). The magnitude of the shear stress of the soil-root matrix obtained at this location obviously higher than un-vegetated soils. The failure at the shear plan crossed by the roots was the same deformation mechanisms with the samples from other 2 locations. Reinforcement of soil by significant high density referring to the high root biomass density of fibrous roots, in this case, increases the strength of soils. (see Figure 12).

Volume of soil Block: $10 \mathrm{~cm} \times 10 \mathrm{~cm} \mathrm{x} 3 \mathrm{~cm}=300 \mathrm{~cm}^{3}$

Biomass $=($ Weight of dry root $) /($ Volume of soil block $)$

\section{B. Root Biomass Density}

The results of the average root biomass density are plotted in Figure 12. Dry root biomass density is the dry weight of roots divided by the volume of the block sample used in the shear test. Figure 12 showed that the highest biomass density indicated from samples at location 3. The other two locations showed slightly different value of $9.4 \%$ in biomass density. Samples from location 2 gave the lowest value of biomass density resulted in lowest shear strength values.

\section{Moisture Content and Particle Size Distribution}

Shear stress is calculated as a function of both vegetal and soil resistance. Vegetal resistance of the soil/plant boundary is calculated as a function of both components including roots density, and soil resistance as a factor of grain size. Vegetal and soil parameters are combined to form the total shear stress resistance of the soil/plant boundary. The soil tests performed in this study were particle size distribution and water content. These two tests seem to be very essential in order to relate soil condition and environment with the growth pattern of the roots.

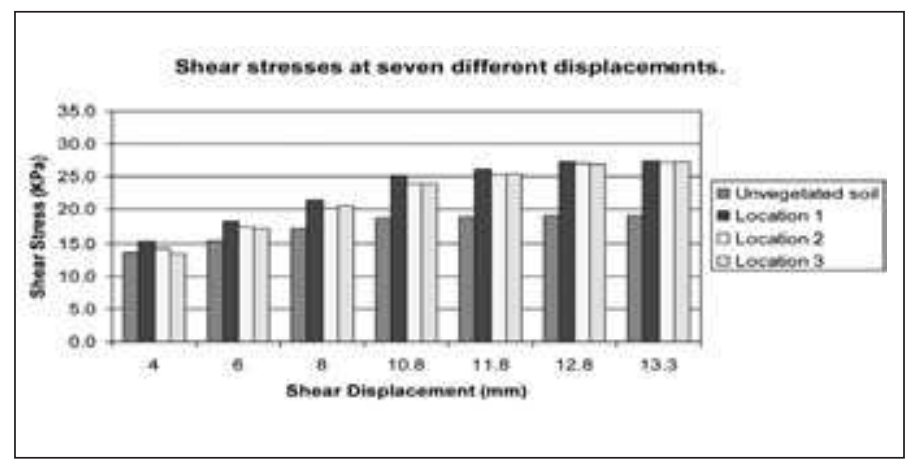

Figure 11: Shear Stresses at Seven Different Displacements

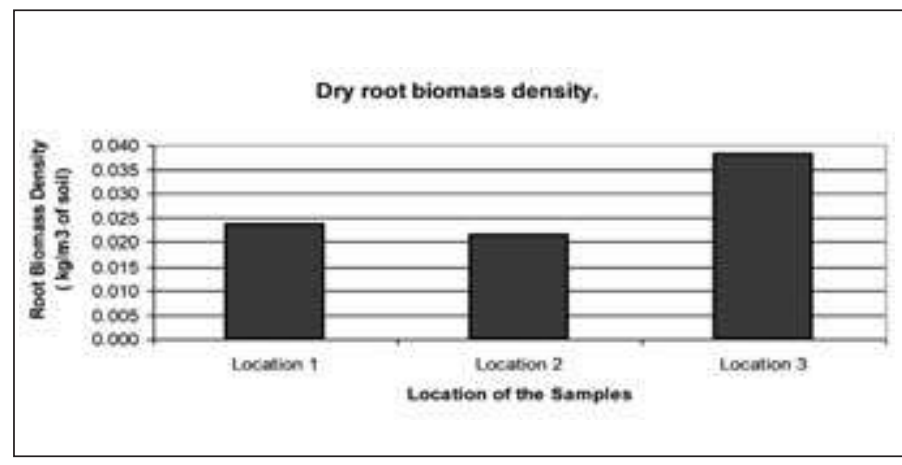

Figure 12: Dry Root Biomass Density.

At the location of typical soil 3, samples of soil were taken at $1 \mathrm{~m}$ radius. It is easy to get the samples from this location because the place was bare and no roots of vegetation in the soil blocks. The roots might affect the results of the test performed. The soil at the site consisted of a poorly cohesive sand which might be derived from the floodplain sediments. The water content indicated also varies with the location of the samples. Sample 3 (M56) gave the highest moisture content; $14.1 \%$ followed by sample 1, M52 and sample 2, M54. Even though the samples come from the same type of soil, the moisture content seemed to be different.

\section{DSCUSSION}

\section{A. Soil-Plant Shear Strength}

The graphs of shear stresses versus displacements show that, in general, the shear stresses were still increasing at the end of the tests. This clearly indicates that root tensile failure did not occur during the shear tests. Root elongation or slippage rather than breakage was the most common condition during failure. This mode of failure was evident in examination of the samples after the testing was completed and has been observed by other investigators studying the effects of fibrous inclusions on noncohesive soils. The steadily increase of shearing resistance of all samples from location 1, 2 and 3 also show that shear stress within the soil was transferred to the roots of vegetation. This phenomenon is influenced by the high fraction of sandy soil occupied by roots. For the herbaceous species tested, the mode and extent of root deformation would likely result in mortality of the plant as the roots were significantly elongated across a nearly uniform plane, hence severing the plants' source of physical anchoring, water, and nutrients. Despite the damage to roots, grass species tested are known to propagate easily from fragments of root and stem tissue that have suitable contact with moist soil, apparently an ecological adaptation to their typical habitat of dynamic riparian corridors where displacement and 
regeneration or relodging downstream would allow survival or new distribution.

Survival and development of plants after a partial failure can readily allow vegetation to provide continued and renewed reinforcement of soils, and also to, in effect, re-compact soils due to matrix suction effects. These roles allow vegetation to limit and manage the amount of ongoing loss and damage that may occur due to experience of some slope failure, unlike fallow soils which remain vulnerable to ongoing mass wasting due to low residual strengths. The shear stresses obtained in each plant species show a very wide spread, making it difficult to come to reasonable conclusions without a suitable statistical analysis. This degree of variation is illustrated, for example, in sample 1 and sample 2 in Figure 8 and 9 or sample 1 and sample 3 in Figure 10. This wide variation is also noted for the un-vegetated soil blocks, 7. This kind of behaviour is expected from samples that were obtained from sites whose natural conditions are variable and uncontrolled. The variation in natural hydrological and geological condition of the site effects might affect the samples. The soil consists of air, moisture and solid and the water content is the ratio of the mass of water to the mass of solids of soils. There are cases where the void ratio is higher than moisture content thus giving wer values in moisture content. The pore air pressure can distort the result. The variation in pore air pressure and pore water pressure in the soil block seemed to give different values of stresses because it related to the water content. Although the whole site are sandy soil, but the moisture content results were not the same. In spite of that, the simple statistic (comparison of mean) test results give valuable information and some general conclusions can be deduced. In this study, the shear box test is not able to control the drainage from the sample or to measure the pore pressure within the sample. Therefore, only stress measurement can be made except when the rate of shearing is kept slow enough to ensure no rise in pore pressure.

Bermuda grass roots in this sandy soil had large reinforcing effect, where the ultimate shear resistance obtained in samples from location 2 and 3 followed in decreasing order by samples from location1. Bermuda grass roots increased soil shear resistance by $27.3 \mathrm{kPa}$ compared to $19.1 \mathrm{kPa}$ for un-vegetated soil at a displacement of $13.3 \mathrm{~cm}$ (location 3 ). The relative strength increase at the same displacement $(13.3 \mathrm{~cm})$ was $43.5 \%$ for location 1 and $42.4 \%$ for location 2 .

The increment of soil strength caused by the roots also had been proven by other researcher before (Abenneth and Rutherfud) [28] where small increase in root density increases the soil shear strength. It was found that the traction effect of the roots increased the tensile strength of the shallow rooted soil by
4.2 5.6 kPa. This finding was true for the samples of soil blocks from location 2 and 3 at displacement $10.8 \mathrm{~mm}$. From this study, the general range of shear strength increment was $0.6-8.3 \mathrm{kPa}$.

Table 1 shows that the shear stresses of the soils permeated with the grass roots at location 1,2 and 3 are significantly different from the un-vegetated condition. Whereas, the shear stresses of soils from location 3 at displacement $4 \mathrm{~cm}$ are not significantly different from the un-vegetated (Figure 11). These root cohesion values are conservative, because they were determined from a shear displacement of $4 \mathrm{~cm}$ and not from the peak stresses, which were never reached during these tests. At the surface, this investigation reveals an obvious relationship between soil shear strength and plants, although statistical analysis dictates that no sweeping conclusions be drawn. Nevertheless, the nature of the conditions, the testing procedure, and the analytical approach are conservative, so it is reasonable to state that the actual role of plants is larger than documented, and that the variability between specimens contributed to the lower degree of statistical validation of the results.

\section{B. Root Biomass Density}

Root biomass density is proportional to the shear strength increase [29]. However, this is true for the plants which have same morphology. As grasses grow, their contribution to a site's stability increases as a function of the speed and ease at which roots "colonise" the soil. This depends on the root content, the roots' material properties, and the morphology or architecture. Root morphology and architecture may be genetically controlled or modified by environmental and adaptation factors. The variation in root biomass can be affected by the variation of the water content. The water content is not constant at different location. This showed how the environment condition can change the value of the root density. As water flows to the soil, mass of adsorbed water formed around the particles. As the water film increases, the particles of the soil can be packed more closely when it is more lubricated. However the pore water pressure in the adsorbed films tends to push the particles apart and so increase the water content.

Strength of roots is also influenced by roots size which is highly dependent on the root density and activity of decay organism. In sandy soil, the moisture movement can move some fine particles. Scouring is the removal of material by surface water. Different density will give different value of root size. In this study all the roots determined were less than $2 \mathrm{~cm}$ which proved the theory by Coppin and Richard where the soil cohesion is limited to the roots up to $2 \mathrm{~cm}$ in diameter [4].

Table 1: Average Shear Stress at Particular Displacement

Average Shear Stress at Particular Displacement (kPa)

\begin{tabular}{|c|c|c|c|c|}
\hline $\begin{array}{c}\text { Location } \\
\text { Displacement }(\mathbf{m m})\end{array}$ & Unvegetated soil & Location 1 & Location 2 & Location 3 \\
\hline $\mathbf{4}$ & 13.6 & 15.3 & 14.2 & 13.5 \\
\hline $\mathbf{6}$ & 15.4 & 18.2 & 17.3 & 17.1 \\
\hline $\mathbf{8}$ & 17.1 & 21.4 & 20.2 & 20.5 \\
\hline $\mathbf{1 0 . 8}$ & 18.7 & 25.1 & 23.9 & 23.9 \\
\hline $\mathbf{1 1 . 8}$ & 18.8 & 26.2 & 25.3 & 25.4 \\
\hline $\mathbf{1 2 . 8}$ & 19.0 & 27.3 & 27.0 & 26.9 \\
\hline $\mathbf{1 3 . 3}$ & 19.1 & 27.4 & 27.2 & 27.3 \\
\hline
\end{tabular}


It is noted that although samples from location 3 had the highest root biomass density, its average maximum shear strength was smaller than location 1 . In fact its shear strength was the smallest one at displacement $4 \mathrm{~cm}, 6 \mathrm{~cm}$ and $12.8 \mathrm{~cm}$. This might indicate that the tensile strength of the roots is smaller than those other roots from other locations although it comes from same species of grass or its root surface friction is lower, hence allowing slippage. However, several other factors such as root orientation, for example, could be the cause for having small shear strength with relatively high root biomass. Figures 12 shows typical shear stress and root biomass density. The species tested showed a fairly well defined shear plane upon failure, with most roots not broken at or near this plane but elongated at increasing strength. Whereas the species at location 1 showed a wider shear zone with numerous roots extending through and beyond this deformed shear zone, they exhibited some stretching and pullout from the adjoining soil matrix.

The relationship between soil condition and root architecture is needed to be taken to consideration. Root architecture relates to the growth pattern which is greatly dependent on the moisture level. The site conditions also influence the rooting habit and growth. The root growth can be analyzed by determining the roots density relying on the biomass as more accurate indicator. The root biomass density was different at each location. Although the soil is considered to be of the same sandy soil, the water contents were different. The result of the water content showed that different locations had different moisture contents. This showed that the growth pattern can be affected differently by the hydrological condition.

Finally, the age of the roots itself can influence the strength and reinforcement of the roots system. The grass was estimated to be 2.5 years old. The root geometry can be limited due to the time from the vegetation grows. The older the vegetations, the denser it will be [30]. Wide variety of the vegetation is influenced by the age of the vegetation.

\section{CONCLUSION}

This investigation generated data about the contribution of selected native plant species (Bermuda grass) roots to soil shear strength. These data can be used to perform qualitative or semi-quantitative assessment of vegetated slopes or slope stability analyses. Soil block samples permeated with roots of plant species that are commonly used in remediation and habitat restoration purposes were tested in a large direct shear apparatus. Shear stress results of rooted soils were compared with results of un-vegetated soil blocks with similar soil types. Un-vegetated soil blocks reached an average maximum force at a displacement of $11.8 \mathrm{~cm}, 12.3 \mathrm{~cm}$ and $13.3 \mathrm{~cm}$. This displacement was used as the ultimate shear stress for the un-vegetated soil. The shear stresses for the root permeated soil blocks were compared to this stress in order to assess the stress increase due to the plant roots. Samples from location 2 and 3 had the largest increase in shear stress, reaching a value of $32.2 \mathrm{kPa}$ at a displacement of $13.3 \mathrm{~cm}$. The maximum shear stress for the un-vegetated soil was just $19.1 \mathrm{kPa}$ at the same displacement. Hence, the root systems of these plants resulted in an increase of strength as compared with fallow soils.

The conclusions from this study are the following:

- The shear stress increase caused by the root system of these plants is significantly different from the shear stress of the un-vegetated treatment. The shear stresses in most of the rooted blocks were still increasing at the end of the test (maximum displacement of about $15 \mathrm{~cm}$ ), indicating that root tensile failure did not occur during the shear tests.

- Additionally, the mode of failure appears to allow for the survival of the herb, and possibly certain woody, species after the event. In general, the shear stress results were very widespread because of the uncontrolled conditions of the natural site conditions of the samples. It is evident that plant roots provide a substantial increase in the shear strength of soils.

- On average, all samples rooted by grass, had a shear stress that was statistically different from un-vegetated fallow soil conditions. The values of soil mass shear strength and root biomass depend on more environmental variables shown by the variation in the moisture content.

- The results and findings from this study are true for the site condition which had inconsistent values of water content. The sandy soil with variation in moisture level tends to give different values of soil-root strength. These show how the relationship between soil and environmental condition can affect the growth of the roots which directly influences the soil-root strength.

\section{REFERENCES}

[1 Gray, D.H. and R.B. Sotir. Biotechnical and Soil Bioengineering Soil Stabilisation: A Practical guide for Erosion Control, Wiley, New York, 1996

[2] Vidal, H. The Principles of Reinforced earth. Highway Research Record No. 282. pp. 1-16, 1969.

[3] Gray, D.H. and A.T. Leiser. Biotechnical Slope Protection and Erosion Control. Van Nostrand Co. NY. 1982.

[4] Coppin, N.J. and Richards, I.G. Use of Vegetation in Civil Engineering. Butterworths. London, 1990

[5] Burroughs, E.R. and Thomas, B.R. Declining Root Strengths in Douglas-Fir after Falling as A Factor in Slope Stability. Research Paper INT-190, 27 pp. Forest Service, I.S. Dept. of Agriculture, Ogden, Utahm 1977

[6] O'Loughlin, C.L. and Watson, A. Root-wood strength deterioration in radiate pine after clear felling, New Zealand Journal of Forest Science, 9(3): 284-293, 1979

[7] Swanston, D.N. and Dryness, C.T. Stability of Steepland. Journal of Forestry. 71(5):246-269 1973

[8] Riestenberg, M.M. Anchoring of thin colluviums by Roots of Sugar Maple and White Ash on Hillslopes in Cincinnati. U.S. Geological Survey Bulletin 2059-E. 1994

[9] Hewitt, J.S. and A.R. Dexter. The behaviour of Roots encountering cracks in soil: Development of a Predictive Model, Plant and Soil. 79: 11-28, 1979

[10] Tardieu, F. Analysis of the Spatial Variability of maize root density. Plant and Soil. 107: 259-266., 1988

[11] Lungley, D.R.,The Growth of Root Systems - A numerical Computer Simulation Model. Plant and Soil. 38: 145-159, 1973

[12] Henderson, R., Ford, E.D. and E. Renshaw. Morphology of the Structural Root System of Sitka Spruce and Computer Simulation of Rooting Patterns. Forestry. 56: 121-135, 1983 
[13] Rose, D.A.The Descript ion of the Growth of Root Systems. Plant and Soil. 75: 405-415. 1983.

[14] Diggle, A.J. ROOTMAP - a model in three dimensional coordinates of the Growth and Structure of Fibrous root system, Plant and soil, 105: 169-178. 1988.

[15] Pages, L. Jordan, M.O. and Picard, D. A simulation model of the three dimensional Architecture of the maize root system. Plant and Soil. 199: 147-154., 1989

[16] Zimmer, W.J. and Grose, R.J. Root Systems and root/shoot Ratios of Seedlings of some Victorian Eucalyptus. Australian Forestry. 22(2): 13-18., 1958

[17] Ashton, D.H. The Root and Shoot Development of Eucalyptus regnans $F$. Meull. Australian Journal of Botany, 23: 867-887., 1975

[18] Dabral, B.G., Pant, S.P. and Pharasi, S.C. Root Habits of Eucalyptus: Some Observation. Indian Forester. 113(1): 11-32. 1987

[19] Stone, E.L. and Kalisz, P.J. On the maximum extent of tree roots. Forest Ecology and Management. 46: 59-102. 1991

[20] Todd R.H. and E.M. Payson,The use of Vegetation in Bioengineered Stream banks: Shear Stress Resistance of Vegetal Treatments. ASCE 1998

[21] Schiechtl, H.M. Bioengineering for Land Reclamation and Conservation. University of Alberta Press, Edmonton, Canada, 1980
[22] Greenway, D.R. 1987. Vegetation and Slope Stability: In Slope Stability. Eds: M.G. Anderson and K.S. Richards. John Wiley \& Sons Ltd, Chichester, pp. 187-230, 1987

[23] Marden, M. and Rowan, D. 1. Protective value of vegetation on tertiary terrain. New Zealand Journal of Forestry Science 2393): 255-263. 1993.

[24] Phillips, C.J. and Watson, A.J. Structural tree root research in New Zealand. Landcare Research Science Series No. 7. Manaaki Whenua Press. 71p. 1994.

[25] Waldron, L.J. The Shear Resistance of root-permeated homogenous and stratified soil, Soil Science Society of America Journal, 1977

[26] Wu, T.H. and Watson, A. In-situ Shear Tests of Soil Blocks with Roots. Can. Geotech. Journal 35: 579-590, 1998

[27] Shewbridge, E.S. and S. Nicholas, Formation of Shear Zones in Reinforced Sand, Journal of Geotechnical Engineering, 122(11) November 1996

[28] Abernethy, B. and Rutherfurd, I.D. The Distribution and Strength of Riparian Tree Roots in relation to riverbank reinforcement. Hydrological Processes, 15(1): 63-79.2001

[29] Ziemer, R.R. 1981. Roots and the Stability of Forested Slopes. Publication, No. 132. International Association of Hydrologic Sciences, pp. 343-361.

[30] Schiechtl, H.M., Bioengineering for Land Reclamation, Alberta Press, 404 p, 1980

\section{PROFILES}

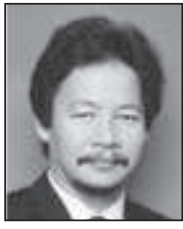

IR. PROF. DR RUSLAN HASSAN Ph.D., P.E. FASc., FASCE, FIEM is presently with the Malaysia Institute of Transport (MITRANS), UiTM leading the Green Logistics group. He researches, consults and teaches Sustainability Design in Practice.

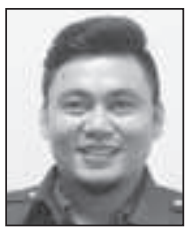

MR. DING IBAU obtained B.Eng (Civil) (Hons) First Class from Universiti Teknologi Mara UiTM). 